\title{
Hardware Progress Made in the Early Flight Fission Test Facilities (EFF-TF) To Support Near-Term Space Fission Systems
}

\author{
Melissa Van Dyke and James Martin \\ Marshall Space Flight Center, National Aeronautics and Space Administration, Huntsville, Alabama, 35812 \\ Tel: (256) 544-5720, Fax: (256) 544-3662; melissa.vandyke@nasa.gov
}

\begin{abstract}
The EFF-TF provides a facility to experimentally evaluate thermal hydraulic issues througin the use of highily effective non-nuclear testing. These techniques provide a rapid, more cost effective method of evaluating designs and support development/risk mitigation when concerns are associated with "non-nuclear" aspects of space nuclear systems. For many systems, electrical resistance thermal simulators can be used to closely mimic the heat deposition of the fission process, providing axial and radial profiles. A number of experimental and design programs were underway in 2004. Initial evaluation of the SAFE-100a (19 module stainless steel/sodium heat pipe reactor with integral gas heat exchanger) was performed with tests up to $17.5 \mathrm{~kW}$ of input power at core temperatures of $1000 \mathrm{~K}$. A stainless steel sodium SAFE100 heat pipe module was placed through repeated freeze/thaw cyclic testing accumulating over 200 restarts to a temperature of $1000 \mathrm{~K}$. Additionally, the design of a 37 -fuel pin stainless steel pumped sodium/potassium (NaK) loop was finalized and components procured. Ongoing testing at the EFF-TF is geared towards facilitating both research and development necessary to field a near term space nuclear system. Efforts are coordinated with DOE laboratories, industry, universities, and other NASA centers. This paper describes some of the 2004 efforts.
\end{abstract}

\section{INTRODUCTION AND BACKGROUND}

Previous Space Technology and Applications International Forum (STAIF) papers (Van Dyke, 2002, 2003 and 2004) describe the benefits of a strong non-nuclear test of nuclear systems program. The purpose of the Early Flight Fission Test Facilities (EFF-TF) is to perform testing on prototypic systems, both at a component and at a system level. Data gained are used to prove concept ideas, benchmark codes, develop fabrication capability, and resolve issues providing risk mitigation. Over its five years of existence, the EFF-TF has performed testing on over 100 individual components and 3 full systems. This paper will describe some of the activities performed in late 2003 and early 2004.

\section{THE TEST FACILITIES}

Experimental testing of components and prototypic assemblies is performed in a 9 foot diameter vacuum chamber (figure 1). The usable internal length is $18 \mathrm{ft}$ and a rail structure/support table provides for mounting of hardware systems. The chamber can reach an ultimate vacuum level in the low $10^{-7}$ torr range or better and is pumped by a combination of four diffusion pumps $(32,000 \mathrm{l} / \mathrm{s}$ each) backed by three roughing pumps $(34,000 \mathrm{l} / \mathrm{min}$ each). Primary test article power is provided by a $1.5 \mathrm{MW}$ switchboard unit (480VAC 3-P) and is distributed to 8 racks of AC to DC power supplies. Each of these racks is equipped with four $15 \mathrm{~kW}$ (150VDC) supplies for a total of 32 supplies capable of delivering up to $480 \mathrm{~kW}$ of power. A master power system program (LabVIEW based) controls the power supplies, regulating the power per supply and providing any special ramping or profiling that is required. This system has been used very successfully to providing high speed power supply response during testing of a core deformation driven reactivity feedback loop (Bragg-Sitton, 2004). The current configuration incorporated on the SAFE-100a system makes use of 5 power supplies (1 for each of the concentric fuel tube rings) providing up to $60 \mathrm{~kW}$ of input power. Data is captured and recorded on a Citadel database system using a number of LabVIEW based virtual instrument programs. A local instrumentation network has been established to route the flow of information in the test facility. Control and feedback signals (valves, pressure transducers etc.) are processed with National Instruments Field Point modules while thermocouple data is processed using an IO-Tech DAQ Scan system currently configured for 168 channels (capacity up to 896 channels). 
Every reactor concept tested in the EFF-TF requires heat removal during operation (e.g. gas heat exchanger on the heat pipe module reactor concept and gas flow through the direct drive gas reactor concept). Two types of gas systems have been setup to satisfy this requirement (figure 2). One is a single pass nitrogen flow loop capable of operation up to $2.4 \mathrm{MPa}$ and delivering flow rates in excess of $0.3 \mathrm{~kg} / \mathrm{sec}$. The second system is a closed cycle helium/argon circulation loop that makes use of a $55 \mathrm{~kW}$ compressor unit to provide up to $0.15 \mathrm{~kg} / \mathrm{sec}$ at $2.4 \mathrm{MPa}$. For both systems, the flow inlet temperature to the article can be regulated by a $94 \mathrm{~kW}$ pre-heater. This heater is capable of providing temperatures up to $480^{\circ} \mathrm{C}$ with a line pressure of $1.38 \mathrm{MPa}$. Gas flow on the single pass system is vented external to the facility; for the circulation system a water heat exchanger is used to cool the hot flow exiting the test article so that it can be passed into the compressor unit.

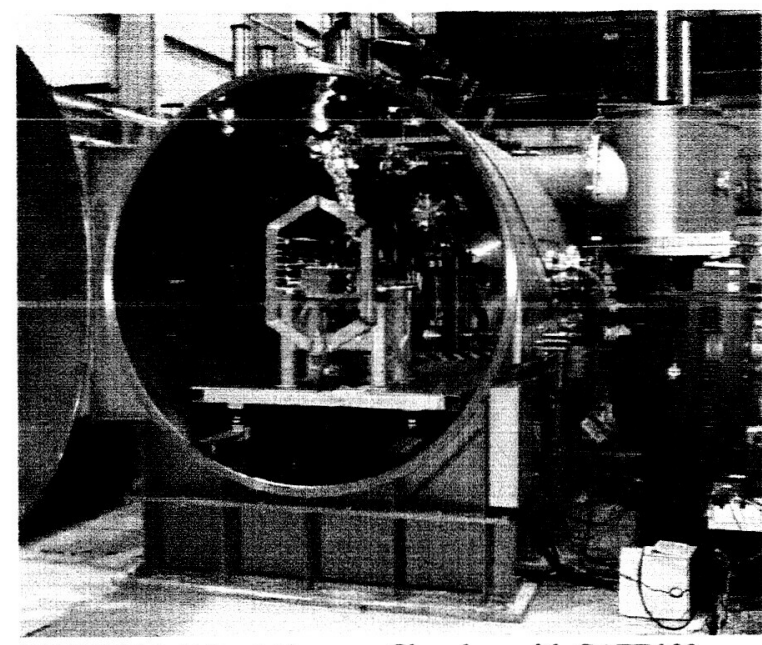

FIGURE 1. 9 Foot Vacuum Chamber with SAFE100a and DDG Inside.

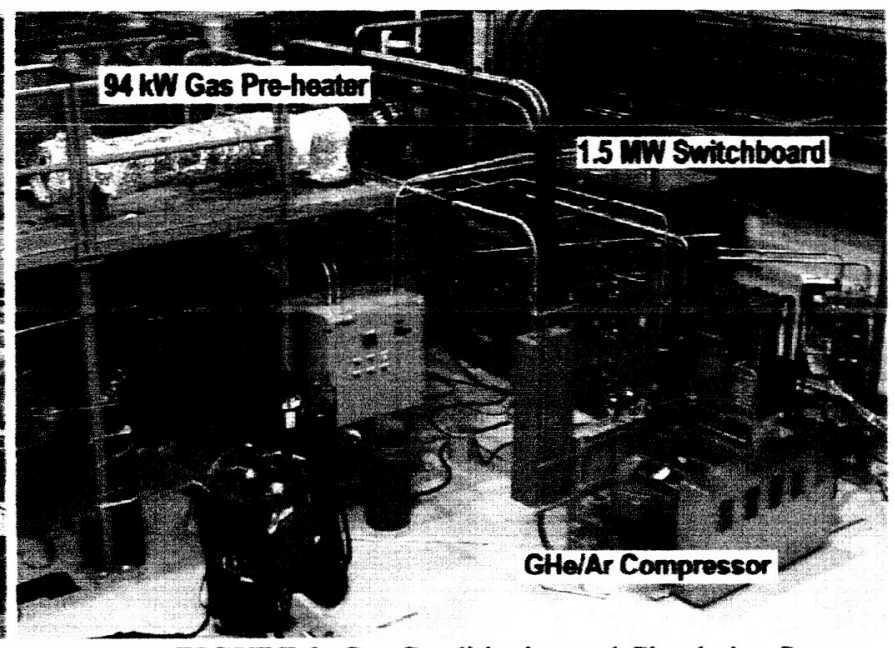

FIGURE 2. Gas Conditioning and Circulation System.

The electrical integration of the simulators into the core has evolved significantly between their introductions in the SAFE 30 to their most recent use in the gas cooled reactor concept. Integration is a function of the reactor type and environment being evaluated. In FY04, efforts were focused on making the integration of the simulators into the core easier (e.g. easier to integrate or change a zone), matching thermal pin conductivities without affecting the test article, and meeting the 0.255 in diameter pin requirement. A concept for a simulator which can match pin conductivity, isolate the simulator from the core to ensure no materials contamination, and make the connection of the simulators easier was designed, fabricated and tested (figure 3 ). This simulator consisted of a graphite heating element brazed into a stainless steel sheath with a gas filled He gap. The sheath was "closed out" with an alumina insulator brazed into the sheath whose dual purpose was to provide a strong mechanical support for the simulator electrical interface and to provide a seal for the GHe. Although there was no mechanical failure of the simulator, it appeared that the GHe did leak out because of the common resistance readings before and after the braze process. Testing continued on the simulators to verify the mechanical strength of the copper to molybdenum and molybdenum to ceramic assembly. The assembly remained intact with no visible damage after hundreds of hours of run time. A simulator concept of 0.255 inches diameter was also demonstrated in FY04. Dozens of simulators were built and tested using various wire combinations. While several tests proved successful, many of the elements "broke-down" at high power levels due to the inability to remove the heat fast enough from the element. The tested element shows promise for small pin diameters and demonstrates excellent axial power profiling capabilities, but the power per pin at temperature appears to be limited. To meet this challenge, efforts began on the research and development of a simulator concept, which uses graphite carbon fiber braid. The fabrication technique involves taking a carbon fiber braid, wrapping it around a mandrel, applying a resin, and melting the mandrel away while simultaneously carbonizing the resin (sets the fiber shape). Preliminary tests were run on carbon braid material wrapped around a mandrel (e.g. verifying material capabilities at temperature); initial results looked promising. Finally, in FY04, simulators for a liquid metal (sodium/potassium) reactor concept have been designed and are currently in fabrication. 


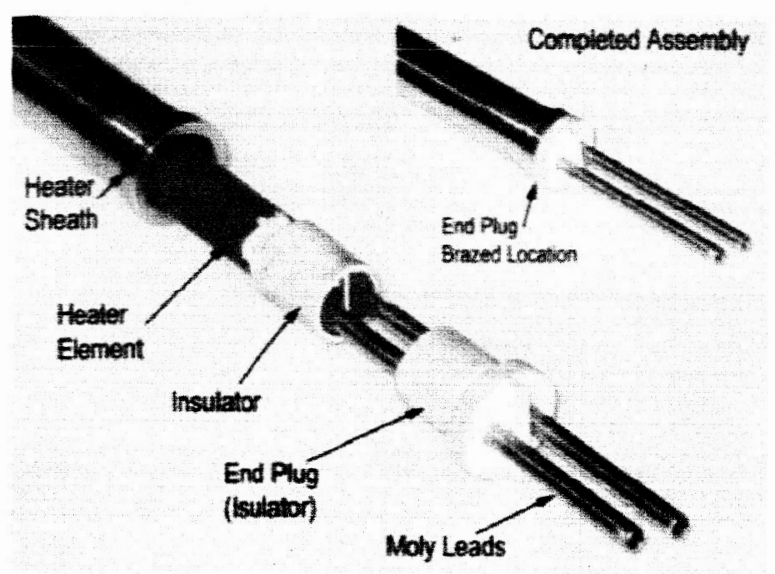

FIGURE 3. Brazed Thermal Simulator Element.

\section{SAFE-100a HEAT PIPE REACTOR TESTING}

A heat pipe system, referred to as the Safe Affordabie Fission Engine (SAFE), has a famiiy of power ieveis, one of which has an output of $100 \mathrm{kWt}$ (SAFE-100). The full SAFE-100 consists of 61 sodium/stainless steel heat pipe modules (183 fuel pins) and operates at a nominal temperature of $973 \mathrm{~K}$ (Van Dyke, 2002 and 2003). The SAFE$100 \mathrm{a}$, a reduced version of the full SAFE- 100 core, makes use of only 19 heat pipe modules ( 57 fuel tubes). The SAFE-100a serves as an initial proof of process and is equipped with an integrated gas heat exchanger. A series of checkouts and tests have been performed on the SAFE-100a include operating the reactor/heat exchanger setup in two configurations: 1) insulated with the chamber at vacuum condition and 2) insulated with the chamber at a background pressure of 20 torr helium (to improve coupling of the heat exchanger and heat pipe condensers). For all tests to date, gaseous nitrogen has been used as the cooling gas for the heat exchanger. Once the closed loop circulation system is completed in the facility, a helium/argon mixture will be used for cooling. Figure 4 illustrates the SAFE-100a system hardware layout (without insulation) and figure 5 shows the system with insulation in place. Figure 6 shows the hardware during typical vacuum test operation (without insulation and glowing).

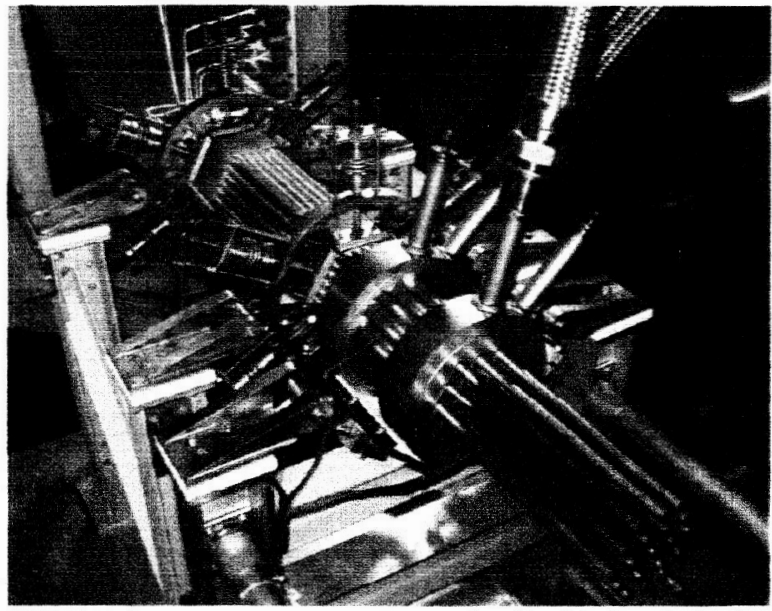

FIGURE 4. SAFE 100a Hardware Config (No Insulation). insulation).

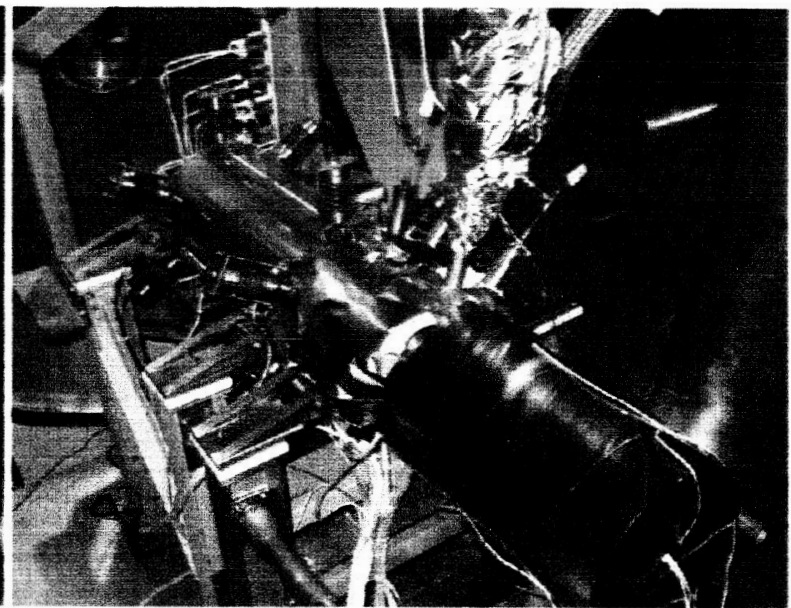

FIGURE 5. SAFE 100a Hardware Config (with

The core and heat exchanger are equipped with instrumentation (pressures and temperatures) so that overall performance can be assessed. The core segment (heat pipe evaporator section) is equipped with 36 internal type $\mathrm{K}$ thermocouple probes (positioned at the core mid-plane) so that the temperature distribution can be monitored. The perimeter of the core and covering insulation are also equipped with thermocouples. For each heat pipe, thermocouples are attached to the condenser (at the evaporator exit) and downstream of the gas heat exchanger. These two thermocouple locations are used to track and verify the startup of each heat pipe. The gas heat 
exchanger covers only $50 \%$ of the available condenser length (the SAFE 100 was designed for two independent gas heat exchangers); the unused heat pipe condenser length is covered with an insulating shell (instrumented with thermocouples). The heat exchanger is equipped with thermocouple probes and pressure transducers at both the inlet and outlet plenums to assess heat extraction performance as a product of mass flow, specific heat and temperature difference. In addition, several temperature measurements are taken along the outer surface of the heat exchanger so that losses can be assessed. Typical heat exchanger operating conditions require pressures up to $1.38 \mathrm{MPa}$, flow rates (for gaseous nitrogen) from 0.06 to $0.09 \mathrm{~kg} / \mathrm{sec}$, and inlet temperatures from 250 to $480^{\circ} \mathrm{C}$.

For initial testing of the SAFE-100a system, five $15 \mathrm{~kW}$ power supplies are used and set up such that one power supply feeds each of the five fuel tube rings (heater locations). This would provide a maximum power input of up to $75 \mathrm{~kW}$ should the thermal simulator wiring connections be configured to produce an optimal resistive load. However, due to the large variation in resistance with temperature for the graphite heaters (approximately $45 \%$ for the temperature range of interest), the selected configuration allows for a maximum of $33 \mathrm{~kW}$ input during startup at $25^{\circ} \mathrm{C}$ increasing to nearly $60 \mathrm{~kW}$ when the core block temperature reaches $750{ }^{\circ} \mathrm{C}$. Power distributed to each zone is controlled by a master power system algorithm (regulates the radial power distribution). A basic radial power distribution was used for these tests; specifically, a flat profile was applied with constant power per fuel pin (all weighting factors used to control peaking or tapering on each zone set to 1.0). Each of the thermal simulators is tapered axially to provide temperature/power peaking (with a cosine relationship) near the center.

The typical startup transient for the SAFE-100a system requires approximately 3 hours. Initial conditions are established in the vacuum chamber (a pressure of $10^{-4}$ torr or a 20 torr helium atmosphere). Once conditions are suitable, the core power is slowly increased and core/heat pipe temperatures are monitored. As core temperature increases and heat pipe condenser temperatures climb, a small gas flow is initiated through the heat exchanger and the inlet line, with the pre-heater temperature adjusted to roughly match inlet temperatures to heat pipe condenser temperature. The heat pipes typically become fully active (albeit at low power throughput) when the core reaches approximately $550^{\circ} \mathrm{C}$. Power is slowly increased until the core temperature required by the test matrix is reached. Once at operating temperature the flow rate and input power are increased together in a stepwise fashion (at each interval, approximately 30 minutes is allowed for the system to equilibrate) while maintaining near constant operating temperature. It is noted that once at the specified operating temperature, loss rates become fixed (regardless of power) since all hardware boundary temperatures that govern conductive, convective, and radiative losses are constant.

\section{SAFE-100a Vacuum Operation Not Insulated}

The initial tests were performed with the vacuum chamber at vacuum conditions. This reduced the thermal coupling to that of radiation for both the heater elements and heat exchanger, reducing the ability to remove heat from the heat pipe condensers while maintaining constant temperature. In addition, it also introduced larger temperature differences among all components (resulting in an increase in thermal stresses). To minimize stress for vacuum testing the core temperature was set to a maximum of approximately $650{ }^{\circ} \mathrm{C}$. At this temperature power input to the core was limited to approximately $8.6 \mathrm{~kW}$.

During typical operation, once both temperature and power levels were reached, a dwell time of 30 plus minutes was allowed to stabilize conditions. At this power level the internal core temperature reached an average temperature of $660^{\circ} \mathrm{C}$ while the heat pipe condensers at the evaporator exit averaged $630^{\circ} \mathrm{C}$ and the condenser section downstream of the heat exchanger an average temperature of $626^{\circ} \mathrm{C}$. At these heat pipe conditions, and with the heat exchanger nitrogen flow rate set to $0.15 \mathrm{~kg} / \mathrm{sec}$, the inlet and outlet temperatures were 330 and 342 ${ }^{\circ} \mathrm{C}$, respectively. Of the total input power of $8.6 \mathrm{~kW}$, approximately $6.0 \mathrm{~kW}$ was transferred into the heat pipe condensers and $1.9 \mathrm{~kW}$ was extracted from the heat exchanger. The difference between the input and extract was lost to the environment (recall that the core was not insulated for these initial tests). The percentage of total input power extracted by the heat exchanger is approximately $22 \%$; this relatively low efficiency was expected due to the poor coupling between the heat pipe and heat exchanger (radiation only). For these tests it was important to keep the temperature difference between the heat pipe condenser and the heat exchanger low (less then $150{ }^{\circ} \mathrm{C}$ ) to minimize thermal induced stresses. An estimate of the heat exchanger inner wall temperature (two small a space for temperature sensors) can be made based on radiation heat transfer calculations. The power transfer is 
represented as a function of the temperature difference between the heat pipe (which operates isothermally) and the final steady state temperature of the inner wall of the heat exchanger. The relationship between total heat transfer and heat pipe/heat exchanger temperature difference is illustrated in figure 7 . Assuming a heat pipe condenser temperature of $630^{\circ} \mathrm{C}$ and a total extracted $\mathrm{HX}$ power of approximately $1.9 \mathrm{~kW}$ results in a temperature difference of approximately $120^{\circ} \mathrm{C}$ (this is a worst case and any solid conduction would tend to lower this temperature difference).

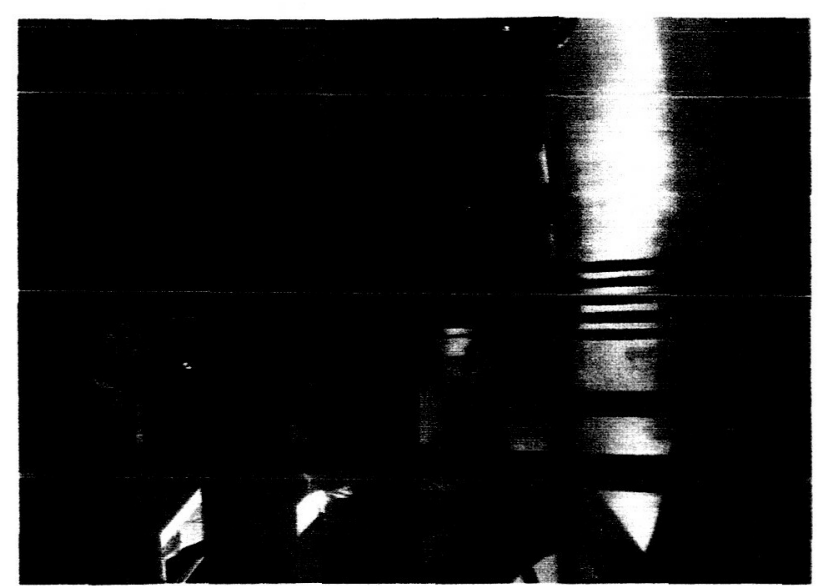

FIGURE 6. SAFE-100a Operation (No Insulation).

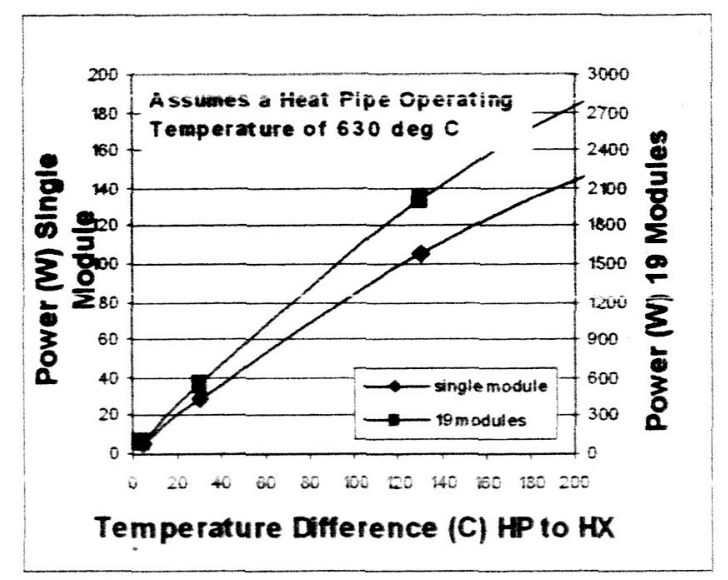

FIGURE 7. Heat Pipe to HX Radiation Coupling.

\section{SAFE-100a Helium Operation Insulated}

The second category of testing required flooding the vacuum chamber with gaseous helium to a pressure of approximately 20 torr, resulting in better thermal coupling between both the heaters/core and heat pipes/heat exchanger. A number of tests were performed with a maximum input power set to $17.5 \mathrm{~kW}$ (limited only by the test matrix, not by either input or output limitation). At this setting, the average core temperature was $720^{\circ} \mathrm{C}$ with average heat pipe condenser temperatures at the evaporator exit of $675{ }^{\circ} \mathrm{C}$ and average condenser temperature downstream of the heat exchanger of $674{ }^{\circ} \mathrm{C}$. At this condition the heat exchanger flow rate was set to 0.091 $\mathrm{kg} / \mathrm{sec}$ with an inlet temperature of $440^{\circ} \mathrm{C}$, producing a corresponding outlet temperature of $570^{\circ} \mathrm{C}$. The increased coupling is apparent in the high gas temperature difference achieved by the heat exchanger. It is also noted that at the higher heat pipe operating temperature (increased sodium vapor pressure) the heat pipe condensers are completely isothermal when comparing the average surface temperatures between upstream and downstream locations $\left(1^{\circ} \mathrm{C}\right.$ variation). For the total input power of $17.5 \mathrm{~kW}$, approximately $13 \mathrm{~kW}$ was extracted from the heat exchanger while the balance was lost to the environment (recall that on this test the core, heat exchanger and heat pipe condensers were insulated). This corresponds to approximately $75 \%$ of the input power being carried away by the heat exchanger. The improved coupling resulted in higher heat exchanger exit temperatures, producing an exit temperature that was only $100^{\circ} \mathrm{C}$ cooler than the heat pipe condenser temperature (indicating that the temperature difference between the inner heat exchanger wall and heat pipe condenser was much less). With the boundary temperatures at equilibrium, it is expected that the loss rates will remain nearly constant at approximately $4.5 \mathrm{~kW}$ as power transfer is increased further while maintaining constant temperature (this will be examined in future testing).

\section{MULTIPLE START/STOP CYCLIC TESTING OF HEAT PIPE MODULES}

A series of tests was performed on a SAFE-100 stainless steel/sodium heat pipe module to examine experimentally the transient response of a single heat pipe module, subjected to multiple start/stop sequences. In total, a single heat pipe module was successfulily subjected to 285 freeze/thaw restart operations; of these, 214 were performed at identical operating conditions. Typical operation included a 1-hour startup to an average evaporator temperature of $735^{\circ} \mathrm{C}$ followed by a 15 -minute hold. Maximum power input during the hold period was $1.9 \mathrm{~kW}$. Between heating cycles, the module was cooled to less then $50{ }^{\circ} \mathrm{C}$ to make certain that all sodium working fluid had completely solidified. The typical duration of a complete cycle was 3.5 hours (a total of 750 hours was required to accumulate the data for 214 restarts). The modules were positioned horizontally during these tests to minimize 
gravitational effects. The automated test setup configured for this evaluation sequenced each phase of the experiment, allowing for around-the-clock operation of the unit. Figure 8 illustrates the hardware setup used to evaluate the module.

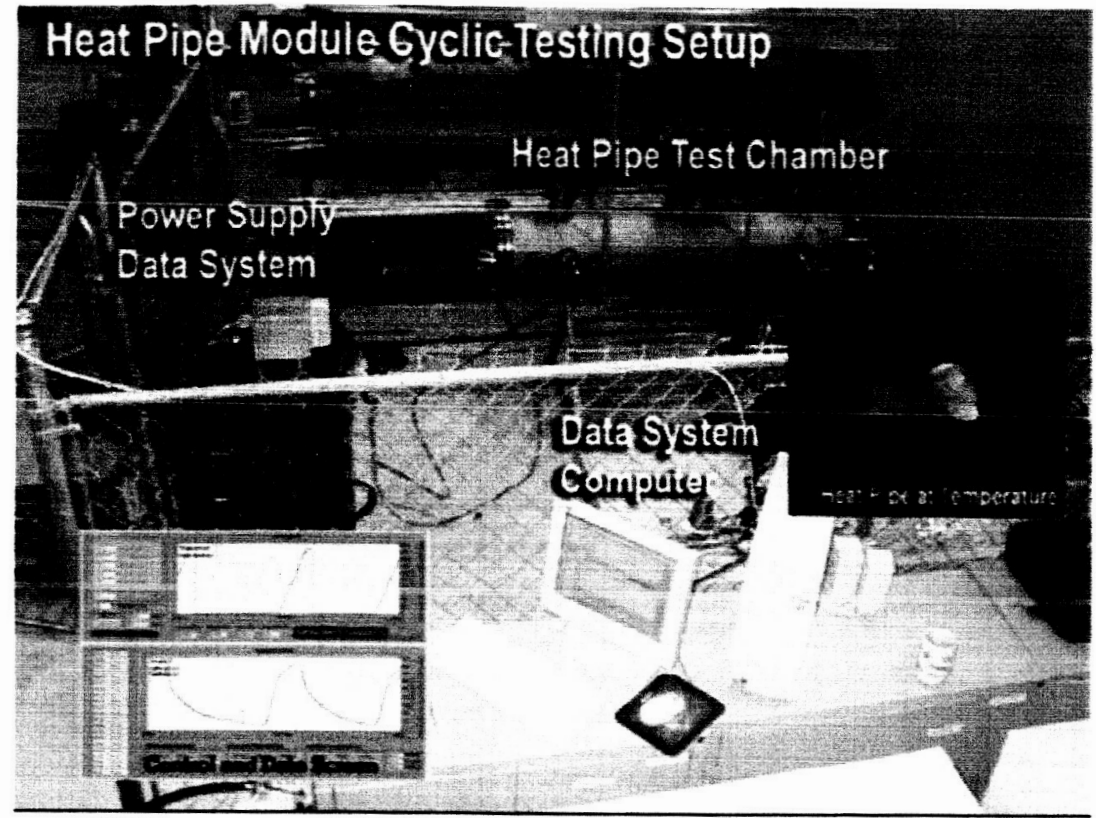

FIGURE 8. Heat Pipe Cyclic Testing Setup.

Results show excellent repeatability in all phases of the heat pipe freeze/thaw sequence and heat pipe performance limits. The particular module selected for these tests was gas loaded with argon (approximately 30 torr), such that its condenser section operated approximately three inches shorter than the full length when at $725^{\circ} \mathrm{C}$. The loaded gas resulted in temperature variations near the thaw front during startup as trapped argon was release randomly. These erratic temperature fluctuations occurred when the evaporate temperature transitioned from 550 to $650{ }^{\circ} \mathrm{C}$ (above $650{ }^{\circ} \mathrm{C}$, the module is fully thawed). Figure 9 illustrates the average measured temperatures for the evaporator and condenser regions during several of the 214 test intervals (cycle numbers $25,50,75,100,125,150$, 175 and 200 ). The data show very repeatable behavior.
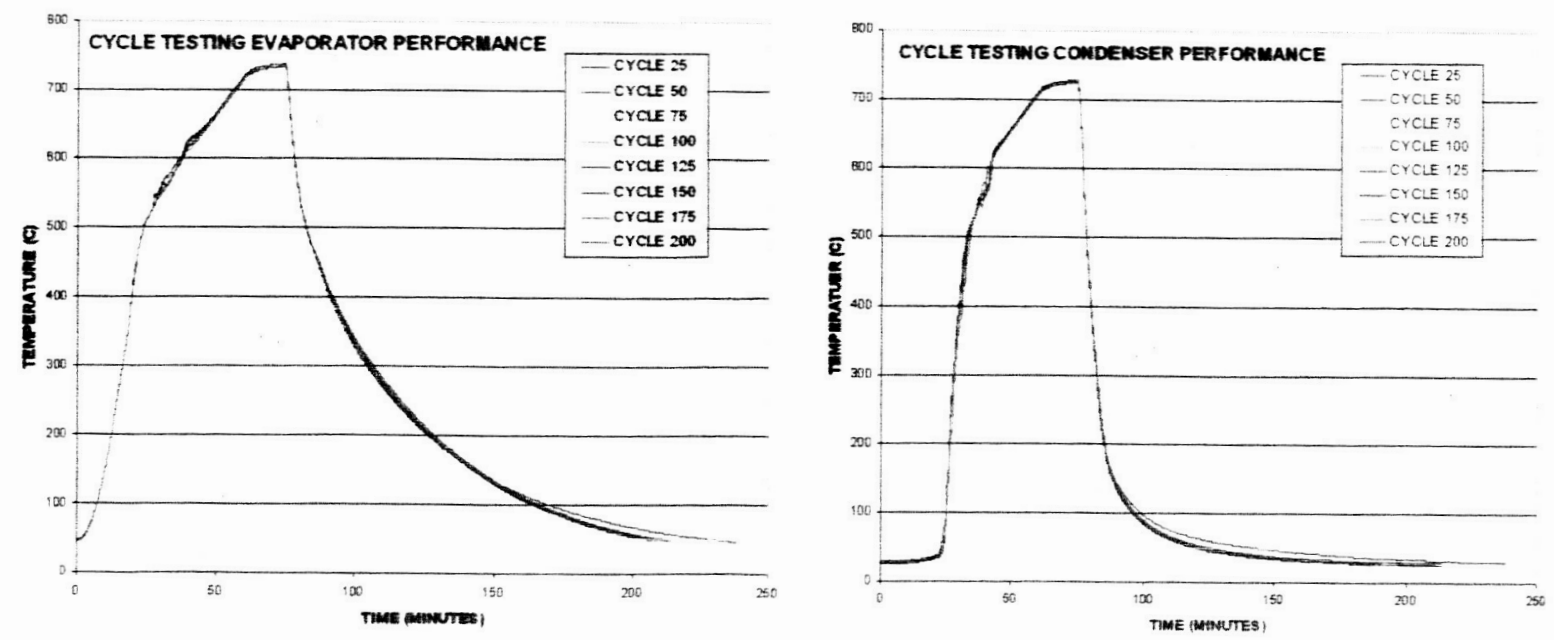

FIGURE 9. Heat Pipe Cyclic Average Evaporator and Condenser Results. 


\section{LIQUID NAK REACTOR DESIGN AND HARDWARE}

To expand the multi-mission technology base related to the use of alkali metal systems for potential surface power application, a small effort was launched within the Early Flight Fission - Test Facilities (EFF-TF) team to design, fabricate and test a pumped alkali metal (sodium/potassium (NaK)) flow loop (Van Dyke, 2004). Basic components of this loop include: reactor segment, $\mathrm{NaK} / \mathrm{GHe}$-Ar heat exchanger, EM liquid metal pump, expansion reservoir, and instrumentation. Only the reactor segment of this loop is prototypic in layout, based on a LANL 100 $\mathrm{kWt}$ design study with 127 fuel pins, a coolant flow of $3.25 \mathrm{~kg} / \mathrm{sec}$ and hot side temperature of $650{ }^{\circ} \mathrm{C}$. However, due to funding constraints, a 37-pin subset of the core, the central 3 rows of pins (pin and flow path dimensions are the same as those in the full design) were selected for fabrication and test. Target nominal core design performance goals for the reduced 37-pin system include a total input power of $30 \mathrm{~kW}$, a coolant flow of $1 \mathrm{~kg} / \mathrm{sec}$, a system pressure drop of less than $8 \mathrm{kPa}$ with a high side core outlet temperature of $650^{\circ} \mathrm{C}$. The general flow schematic with primary components is illustrated in figure 10. Engineering drawings were produced based on design requirements resulting in the final layout as shown in figure 11 . All components were custom machined from 316 stainless steel and the pump is a commercially available MSA Style VI unit supplied by Creative Engineers Inc. All plumbing and components were laid out such that the unit can be completely drained; this required that the system be configured on a tilt table that can be rotated through an angle of 4 degrees. The focus of this project is to keep the overall layout simple, serving as a "test bed" so that hands-on experience can be gained through rapid fielding of hardware. Once operational, this system provides an excellent platform that can be adapted to test specially designed components (heat exchangers, pumps, alternate core assemblies, etc.) that are more prototypic of flight type units. Initial plans are to fill the system with NaK-78 (the eutectic which is a liquid at room temperature). It is possible to fill the unit with sodium, but allocations will be required to supplement the system with trace heaters and to accommodate freeze/thaw expansion issues. Lithium could be pumped, but only to a temperature of 400 to $450{ }^{\circ} \mathrm{C}$ due to compatibility issues with stainless steel at high temperatures (there may be additional instrumentation issues with pressure transducers).

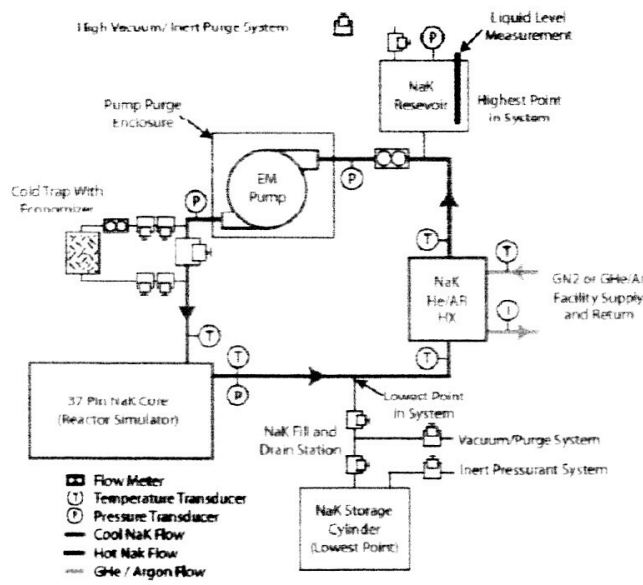

FIGURE 10. NaK Core Flow Paths.

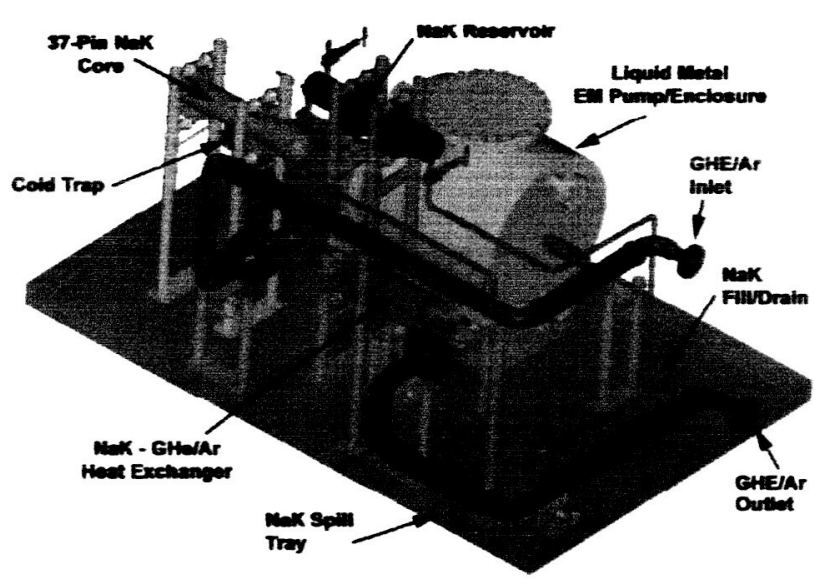

Figure 11 EM Pump Layout.

\section{SUMMARY}

Through component and systems testing (over 100 different components), data gained in the EFF-TF is used to prove concept ideas, benchmark codes, develop fabrication capability, and resolve issues providing risk mitigation. Through step-wise approaches in testing (building on the successes of the previous year), the EFF-TF performed prototypic testing on prototypic systems, both at a component and at a system level. Data gained were used to prove concept ideas, benchmark codes, develop fabrication capability, and resolve issues providing risk mitigation. 


\section{ACKNOWLEDGMENTS}

The author wishes to acknowledge the substantial contributions to the design and fabrication of hardware from the following personnel at LANL: Robert Reid, Mike Houts, Rick Kapernick, Ray Guffee, Gordon Wilcutt, Dave Poston and James Lee. The author also wishes to thank the EFF-TF team at MSFC who is responsible for taking the LANL inputs and turning paper into reality: Thomas Godfroy, Shannon-Bragg-Sitton, Boris Stanojev, Roger Harper, Gene Fant, Stan McDonald, Pat Salvail, Brian Steeve, Bruce Askins, Joe D. Davis, Dalton Nguyen, Robert Carter, Ricky Dickens, and Omar Mireles. Finalily, the author wishes to thank the following industry partiners who have contributed greatly to the success of the building of the hardware: Advanced Method and Materials and LUNA innovations.

NASA's Project Prometheus, the Nuclear Systems Program, supported the work described within this paper, in whole or part, as part of the program's technology development and evaluation activities. Any opinions expressed are those of the author(s) and do not necessarily reflect the views of Project Prometheus.

\section{REFERENCES}

Bragg-Sitton, S., and Forsbacka, M. (2004). "Application of a Virtual Reactivity Feedback Control Loop in NonNuclear Testing of a Fast Spectrum Reactor." International Congress on Advanced Nuclear Power Plants (CAPP-2004), Pittsburgh, PA, Paper 4279.

Van Dyke, M.K., et al., "Phase 1 Space Fission Propulsion System Testing and Development Progress," in Proceedings of Space Technology and Applications International Forum (STAIF-2002), edited by M.S. El-Genk, AIP Conf proceedings 608, AIP, New York, 2002, pp 692-697.

Van Dyke, M.K., et al., "Test Facilities in Support of High Power Electric Propulsion Systems," in Proceedings of Space Technology and Applications International Forum (STAIF-2003), edited by M.S. El-Genk, AIP Conf proceedings 654, AIP, New York, 2003, pp $451-456$.

Van Dyke, M.K. " Non Nuclear Testing of Reactor Systems In The Early Flight Fission Test Facilities (EFF-TF)." International Congress on Advanced Nuclear Power Plants (ICAPP-2004), Pittsburgh, PA, Paper 4276. 